\title{
Atlantis
}

Critical Studies in Gender, Culture \& Social Justice

Études critiques sur le genre, la culture, et la justice

\section{Allegories of Gender: Transgender Autology versus Transracialism}

\section{Aniruddha Dutta}

Volume 39, numéro 2, 2018

URI : https://id.erudit.org/iderudit/1064075ar

DOI : https://doi.org/10.7202/1064075ar

Aller au sommaire du numéro

Éditeur(s)

Mount Saint Vincent University

ISSN

1715-0698 (numérique)

Découvrir la revue

Citer cet article

Dutta, A. (2018). Allegories of Gender: Transgender Autology versus Transracialism. Atlantis, 39(2), 86-98. https://doi.org/10.7202/1064075ar
Résumé de l'article

This article explores how race and gender become distinguished from each other in contemporary scholarly and activist debates on the comparison between transracialism and transgender identities. The article argues that transracial-transgender distinctions often reinforce divides between autological (self-determined) and genealogical (inherited) aspects of subjectivity and obscure the constitution of this division through modern technologies of power. 


\section{Special Section: Research}

\section{Allegories of Gender: Transgender Autology versus Transracialism}

Aniruddha Dutta is an Assistant Professor in the departments of Gender, Women's and Sexuality Studies and Asian and Slavic Languages and Literatures at the University of Iowa. Dutta's research interests lie in globalization, development, gender, and sexuality, particularly the institutionalization of gender and sexual identity politics in India. Their work has appeared in journals such as International Feminist Journal of Politics, Transgender Studies Quarterly, and South Asian History and Culture. Their current book project, Globalizing through the Vernacular: The Making of Gender and Sexual Minorities in Eastern India, explores the role of seemingly peripheral or "local" communities, networks, and subcultures in the globalizing expansion of liberal democratic discourses of gender/sexual identity and rights, studying how this process transforms, reconfigures, or reproduces structural hierarchies of language, class, caste, and citizenship.

Abstract: This article explores how race and gender become distinguished from each other in contemporary scholarly and activist debates on the comparison between transracialism and transgender identities. The article argues that transracial-transgender distinctions often reinforce divides between autological (self-determined) and genealogical (inherited) aspects of subjectivity and obscure the constitution of this division through modern technologies of power.

Keywords: transracialism; gender identity; autology

\section{Introduction: Two Scenes of Transgender Recognition}

Let me begin with a scene that might seem quite removed from the North American debate on "transracialism" and the highly contested (dis)analogy between transgender and transrace identities ${ }^{1}$. In late 2016, the Indian government introduced a bill on transgender rights titled the Transgender Persons (Protection of Rights) Bill 2016. The bill attracted many criticisms from transgender activists in India. Many activists strongly protested the bill's decree (later revised) that people would need to be certified by "district screening committees," including psychiatrists, to be legally recognized as transgender (Orinam 2016). However, activists have been divided on the issue of what should take the place of such screening committees. Some activist collectives lobbied for a fully self-determined process through which trans people should be able to legally change their gender to male, female, or transgender/other, sans screening and irrespective of transition (THITS 2016). Other trans activists worried that without a screening process altogether, cisgender people could claim to be trans to gain welfare measures. Among them, some expressed concern that the inclusion of "genderqueer" within the transgender category in the bill might be misused by gay or lesbian people to claim trans identification, thus excluding underprivileged trans people truly deserving of welfare (Dutta 2016). This is a particularly fraught question given that many South Asian gender-variant communities like kothis, dhuranis, and hijras include a spectrum of people, including those who might be described in Anglophone terms as feminine same-sex-desiring men, trans women, and people with fluid or overlapping subject positions, thus defying neat cis-trans binaries (Dutta and Roy 2014). In that context, the recognition of 
"transgender" as a legal category invested with rights and benefits spurs anxieties on part of both the state and communities regarding the proper subjects of such recognition.

Cut to the United States, where the increasing representation of trans identities in mainstream media and culture has been hailed as a "transgender tipping point” (Penny 2014). In April 2015, even as this moment was unfolding in US popular culture, trans writer Meredith Talusan was interviewed for an article in the now-defunct feminist website The Toast, where she was asked about her conception of gender identity and selfhood. Talusan departed from common narratives of transgender identity as innately determined from childhood, and provided a nuanced account of how she came to identify as a woman informed by both her subjective traits and her sociocultural context:

I'm not the type of woman who believes that there is something unchanging about me that makes me a woman. Mainly, I'm a woman because there are huge parts of me that have come to be coded in this culture as feminine, and that this culture makes so difficult to express unless I identify as a woman. Even when I identified as a gay man, I felt so much pressure to be masculine . . . and I was only allowed to be feminine as a parody. . . . So to be the kind of feminine I wanted to be in this culture, I felt the need to identify as a woman and I don't regret that decision because women are awesome. (Jerkins 2015)

Later that year, the "transgender tipping point" took an unexpected turn when controversy erupted over the racial identity of Nkechi Amare Diallo (formerly known as Rachel Dolezal), who was exposed as having white parentage after years of representing herself as black (Koerner and Dalrymple 2015). Several commentators, including Diallo herself, described her claim to blackness as analogous to trans people's claims to be a different gender relative to their social gender assignment (Allen 2015). In this context, Talusan joined a chorus of trans and people-of-colour
(POC) voices that quickly rebuffed comparisons between Diallo's identity and trans narratives, writing, "the fundamental difference between Dolezal's actions and trans people's is that her decision to identify as black was an active choice, whereas transgender people's decision to transition is almost always involuntary. . . . Dolezal identified as black, but I am a woman, and other trans people are the gender they feel themselves to be" (2015). Talusan thus backtracks from her previous statement about her womanhood as a consciously self-determined identification rather than an unchanging essence: now gender is posited as an involuntary, static and inherent aspect of subjectivity.

The striking contrast between Talusan's former and latter statements is symptomatic of the anxieties surrounding trans recognition at a moment when "transgender" is being increasingly absorbed into liberal regimes of governance and mainstream forms of cultural representation around the world. As the brief comparison between the Indian and US contexts indicates, the transnational spurt in trans visibility prompts a tense reckoning with the implications of trans recognition and whom it might legitimately encompass or not. The controversy around Diallo's claims demonstrates how the stakes of the governmental and social recognition of transgender identities extend well beyond the specific case of gender. Indeed, the increasing incorporation of trans identities into liberal governance regimes, coupled with media visibility, has positioned transgender narratives as paradigmatic models for various forms of identification that go against social assignment. As Susan Stryker (2015) says regarding the transgender-transrace analogy:

Perhaps the very first question to pose here is how discourses and narratives rooted in transgender history and experience have come to supply a master story for other kinds of bodily transformations. . . . How is it that transgender stories have become well known enough, relative to other claims of identity transformation, to function as the better-known half of the pair? 
In response to the invocation of transgender as a legitimizing narrative for transracialism, many journalists, scholars, and activists have responded by insisting not only that race and gender identity operate in fundamentally different ways, but also that the transgender-transrace analogy perpetuates harm on people who are oppressed in gendered or racial terms. For instance, Samantha Allen (2015) argues that unlike gender, racial transition is simply not possible except as an exercise in cultural appropriation and white privilege. She goes on to aver that Diallo's attempt "to pass as someone whose identity deserves respect on the same grounds as transgender people. . . has the potential to do real damage to public perceptions and conceptions of transgender identity." In the academic context, transrace-transgender analogies have been critiqued as abstract theoretical exercises that ignore the material lived experiences and knowledges of trans people and POC, as was suggested by the open letter to Hypatia asking for the retraction of Rebecca Tuvel's 2017 article "In Defense of Transracialism" (Open Letter 2017). In a review of Rogers Brubaker's book Trans: Gender and Race in an Age of Unsettled Identities, C. Ray Borck says:

In Tuvel's case as in Brubaker's, just because it is conceptually possible to cull a logic from the most banal of pop-cultural encounters with transgender and apply it to a sociologically nonexistent thing called transrace doesn't mean that doing so produces any kind of knowledge illuminating actual gendered or raced lives, histories, material realities. ... Even if we are in a moment in which transrace is emerging as an identity category... I maintain that our best methods for understanding what it is or means will not be best produced by taking transgender as the point of departure or comparison. $(2017,684)$

In this context, it is perhaps germane to reframe Stryker's question as such: What is at stake in dissociating transgender from such analogical uses, in not letting it be a referential narrative for other, more controversial, identity claims? If on one side transgender emerges as a "master story" invoked for the validation of what is currently socially unacceptable, on the other, trans is sought to be maintained as a sacrosanct narrative of ontologically valid identification that should not be contaminated through comparison with "sociologically nonexistent" phenomena. This ignores how transgender has not always been a sociologically validated or legible category. As Adolph Reed (2015) puts it, "transgender wasn't always a thing-just ask Christine Jorgensen." Further, as the contested inclusion of genderqueer within the transgender category in India suggests, not all trans identity claims are likely to be treated the same, and some are more sacrosanct than others, depending on factors like conformity to a binary transitional narrative or lack thereof. The deeper issue, then, is to parse the conditions of legibility that permit identity claims to be recognized as valid or not, particularly in the realms of critical scholarly and activist discourse.

I here draw inspiration from trans and POC scholars who have cautioned both against analogical conflations of transrace and transgender, and against some of the ways in which the transrace-transgender analogy is shut down. As Kai M. Green says, simply saying that "race and gender are not the same" might serve to re-naturalize gender such that "transgender can become a category that we take for granted" (2015). Paisley Currah (2015) notes that some attempts to shut down the transrace-transgender comparison reduce "trans politics and claims to identity" to the "most simple minded versions of trans essentialism." A comment underneath Stryker's aforementioned post (2015) provides a neat example: transrace and transgender are "not comparable ... . [because] trans is an actual medical condition. These people have different hormones in their body that cause them to feel like the other gender." Such claims are part of a biologically deterministic etiology or causal narrative of gender identity that is widely prevalent in both the medical establishment and popular culture. Indeed, transgender legibility in the mainstream has been often premised on the etiology of a predetermined brain sex that manifests itself through anatomical dysphoria right from one's childhood, which serves to maintain a deeply biologized ontology of 
gender (Tannehill 2013). It is this kind of an etiology and ontology that Diallo sometimes evokes to validate her "transracial" identity based on an innate racial disidentification with whiteness from her childhood, but far less successfully (Kim 2015).

However, it is not only biological essentialists who have bristled at transgender-transrace analogies; indeed, many critics position themselves against the biological determinism of both race and gender, and rather locate their objections in the dissimilar sociohistorical constructions and lived experiences of these categories. For instance, race is understood as a more recent colonial construction that functions more as an externally imposed taxonomy rather than deep subjective identification (Anderson 2017), whereas gender is apparently an older, more cross-cultural construct, and a more essential part of core selfhood (Talusan 2015). However, as suggested by Talusan's oscillation between essentialist and non-essentialist understandings of gender identity, I contend that commentators have not always been transparent about their own role in such processes of construction. That is to say, transrace-transgender distinctions are not merely attempts to understand external social realities but actively work to construct race and gender in ways that merit further exploration.

In particular, I am interested in how the relation between socially assigned categories, material position within hierarchies of privilege, and subjective identification is understood in different ways for different identity claims. I would argue that a key reason for the discomfort with transrace-transgender analogies lies precisely in the way that gender identity has been de-essentialized and the aspects of social position and subjective identity have been delinked from each other through critical discourses and activist struggles. Gender has been individualized, interiorized, and dissociated from both biological and social determinism to a greater degree relative to other axes of identity, permitting ontological justifications of gender identity that are not based on fulfilling external material criteria. In that regard, the dissociation of transgender and transrace narratives serves as an allegory that might help us to parse the contemporary reconstruction of gender in contrast to other forms of identification. With reference to Elizabeth Povinelli's analytical distinction between "autology" and "genealogy” (2006), I specifically examine the constitution of gender as both ontologically deeper and more autological or self-determined relative to the genealogical determination of race. The attempt to examine how this division is constituted in contemporary discourses on transracialism is not to adjudicate transrace identity claims as valid or otherwise, nor to lay out an abstract theory of race and gender over the lived struggles of racially or gender marginalized people. It is rather to tease out what becomes taken for granted in our affective and intellectual responses to the transrace versus transgender question.

\section{On Materiality and Identity}

While the historical dynamics and social materialities of race and gender are undeniably different, there is at least one common question at stake in debates about racial and gender identity claims. This is the relation between social position in its material and experiential aspects (the lived experiences and privileges/disprivileges resulting from one's placement within socially assigned categories) and subjective identification. In which cases does a distinction between social position and subjective identity become not only analytically useful, but also politically acceptable? This is a question that turns up, for instance, in debates about trans women having allegedly experienced male privilege, or about Diallo's white privilege in relation to her claim to blackness.

Rather than tackling this question with reference to race or gender right away, it might be illuminating to begin from an analytical and political category that has been rather neglected in the debates on transracialism: class. In the predominant genealogy of class critique that comes to us via Marxist theory, class is glossed as a collective relation to the social means of production (Marx and Engels 1945). In the Marxist framework, it would make no sense to self-identify as 
a particular class, especially when one's subjective identity is at odds with social position. For instance, in the US context, many rich people say that they are middle class (Frank 2015). However, for the purposes of political economic analysis, only change in one's material circumstances would correspond to a valid change in class position. Since the very definition of class is in terms of an external position within socioeconomic relations, one could argue that it is a materially determined category and not an individualized identity at all, even though that is how it is often glossed in American intersectionality speak.

If the evocation of class seems a bit far-fetched in this discussion, it would be instructive to recall that some versions of radical feminism have indeed conceptualized gender in terms of class relations: one's relation to the biological means of reproduction determines the sex class that one is socially placed within at birth (Firestone 1970). Contemporary TERFism, or trans exclusive radical feminism, extends such arguments to deny the validity of transgender identities. One's sex class is seen as an immutable socially determined reality, resulting in a rigid binary division of privilege and disempowerment: there is no subjective reality to gender; rather gender is merely an ideological construct that keeps the sex classes intact. Therefore, subjective gender identification is not valid, and trans identity serves to deny the material determination of assigned sex (Barrett 2016). In practice, this means that trans women deserve to be exposed as bearers of male privilege and non-binary people simply cannot exist.

Activist and academic discourses have powerfully refuted such a deterministic materialism of sex/gender. More mainstream trans discourses have done this by positing an alternative form of material determination through essentialist etiologies such as brain sex which prompt and justify bodily transition, thus biologically and socially dissociating trans people from their socially assigned gender (Tannehill 2013). The deep ontological reality of trans women as women, and their anatomical transition to their authentic self, dissociates them from male privilege (Thom 2015).
However, recent trans activism has moved away from biologized etiological and ontological narratives hinged on bodily transition. Trans activist-academic discourses have increasingly shown that the materiality of gender as both socially perceived and subjectively lived is often contextually changeable, intersectional and non-binary, rather than materially determined into rigidly binary social classes. For instance, trans feminist Kat Callahan (2013) posits the idea of "provisional male privilege": privilege does not simply follow from having male-assigned bodies, but rather is linked to the performance of hegemonic masculinity, which often excludes trans and queer people. Indeed, the co-constitution of gender with class and race means that even cisgender maleness is not always a privilege in itself and some cis men might end up having less privilege than elite women, as evident in the persecution and criminalization of Black men and masculinities through the US carceral complex.

Further, trans activists and scholars have also increasingly forwarded a distinction between subjective identification and the presence or absence of gendered privileges. This became particularly apparent after the famed feminist author Chimamanda Ngozi Adichie (2017) made statements about all trans women having had male privilege at some point in their lives. Some trans feminists like Jen Richards (2017) went beyond the defense against the charge of male privilege, and pointed out that trans women, like any other gendered group, may have very different narratives and histories of gender (dis)privilege. While some trans women experience little or no male privilege due to early visibility or transition, others like Caitlyn Jenner and Richards herself have grappled with male privilege for much of their lives, both benefitting from and suffering due to their social assignment as upper-class white males. Irrespective of the degree of privilege, however, material position is not seen as the determinant of their identity both before and after transition.

Indeed, the role of bodily transition and social passing is also increasingly downplayed relative to self-identi- 
fication in trans discourses. As Asher Bauer (2010) says, "sex is as much a social construct as gender, as much subject to self identification ... while (anatomical) modifications may be necessary for our peace of mind, they are not necessary to make us 'real men' or 'real women' or 'real' whatevers." Moreover, the proliferation of genderqueer and non-binary discourses have foregrounded ever more fluid configurations of subjective identity and gender expression. Trans advocates on popular feminist websites like Everyday Feminism have argued that genderqueer people need not look androgynous, and presentation as cisgender need not coincide with cis identification (Reading 2014). In diametrical opposition to the materialist determination of sex advanced by TERFs, such advocates argue that gender should be neither defined by anatomy nor by looks or dress, but rather, only by how one identifies: gender identity is posited as entirely self-determined and need not meet any external social criteria (Micah 2015).

This tendency is also evidenced in the aforementioned Indian debate over transgender rights legislation. Some activists have advocated a dual system of recognition where legal gender identity as male, female, or other is based entirely on self-attestation, without having to fulfill external criteria of transition. However, to access benefits from the state, one has to be vetted by committees led by community members who would presumably take factors such as gender expression, caste, and class into account (THITS 2016). The distinction between legal identity and certification for benefits carries the privilege-identity distinction to its logical conclusion, and seeks to formalize it into legal procedure: the state cannot adjudicate identity claims based on external assessments of social identity or position, but the lived experience of (dis)privilege remains a valid consideration for accessing benefits.

There is a stark contrast between the disaggregation of self-identification and external material position in the case of gender and the deterministic approach to racial identity in progressive spaces. While race is commonly acknowledged to be sociohistorically con- structed, it seems to function as a materially determined reality akin to class in Marxist political economy, where any valid sense of subjective identity can only follow from the social predetermination of one's racial position. As Zeba Blay says, "racial divisions may ultimately be a construct . . . but 'skin color is hereditary.' And it's skin color that primarily determines racial privilege" (2015). Further, unlike the case of class, where agential economic mobility is possible, the material determination of race is typically assumed to be fixed; any transformation in racial position does not seem to be feasible, and any attempted change can be seen only as dissimulation. This is apparent in a stream of commentary on Diallo which sees her actions as always perpetuating white privilege, which remains immutable irrespective of anything that she might do (Blay 2015; Millner 2017). As Blay puts it, "transracial identity . . . allows white people to indulge in blackness as a commodity, without having to actually engage with every facet of what being black entails ... Dolezal retains her privilege; she can take out the box braids and strip off the self-tanner and navigate the world without the stigma tied to actually being black" (2015). In the academic context, Kris Sealey disagrees with Rebecca Tuvel's contention that Diallo's actions might amount to a "renunciation of white privilege" $(2017,271)$; Sealey instead reiterates that "Dolezal's decision to reject her privilege ... ultimately affirms that privilege in her very decision to reject it (the privilege lies in having the option to say 'yes' or 'no')" (2018, 26). Both Blay and Sealey underline that such an option is typically not available to black people, and that transition from black to white is often much more fraught and risk-laden, as evidenced in historical cases of black people passing as white for survival.

My point here is not to defend Diallo's identity claims against charges of white privilege, nor to deny that the variable access to racial transition and "passing" is contingent on social privileges or lack thereof (which is also true of gendered transition in a different sense, where class and economic ability often determine both the access to and the quality of transitional treatments). There are certainly points where Diallo's 
self-representations seem liable to the charge of privileged opportunism; for instance, Diallo seems to have previously claimed discrimination based on whiteness (Allen 2015). However, the critique of Diallo's identity claims often extends far beyond her narrative to the ontological dismissal of transrace per se as "not a thing" (Blay 2015) and as "sociologically nonexistent" (Borck 2017, 684). This shows how Diallo's story has served as a particularly limited and limiting narrative that has constrained discussions of racial fluidity in the US. As the Afro-Jewish philosopher Lewis Gordon points out, "people have been moving fluidly through races since the concept emerged in its prototypical form" $(2018,14)$. Beyond the case of passing for survival, Gordon cites various other examples of racial mobility: groups such as Irish Americans or Greek Americans "achieving white identity," but also individuals from these communities who followed different trajectories and became black through socialization, or were known as black to begin with (15). Such collective and individual trajectories of racial transformation have been evoked only marginally in the debate on transracialism. Diallo's extraordinary visibility, resulting in continuous media coverage and a book contract, demonstrates her privileged status that serves to invisibilize other agential negotiations with race. One may object that these other narratives do not explicitly claim transracial identification, but neither did Diallo until after her dramatic outing: initially she even distanced herself from the term "transracial" (Moyer 2015). Cressida Heyes notes that individual motivations for changing social or legal race, particularly whether people seek to merely pass as a different race or conceptualize a different racial identity, are often unclear in the historical record $(2009,143)$. Ironically, wholesale dismissals of transracialism and the reduction of agential racial transformation to Diallo's case-for instance, Borck $(2017,684)$ says that transrace as a category has just one exemplar-recenters her in discussions about racial fluidity and reinforces the privileged status of identity narratives originating in white American contexts.

Given that the dismissal of transrace on the basis of
Diallo's story only bolsters her representational preeminence, could one reframe the issue to separate the question of her material privileges from the ontological question of transracialism? This calls for an interrogation of why the distinction between subjective identification and the materiality of social position does not seem feasible for transrace narratives. Why does it become so difficult to separate the critique of Diallo's actions from the dismissal of transrace, both in her case and as a whole? Why does not a privilegeidentity (or materiality-subjectivity) distinction emerge here in the way it does for gender? I do not seek to offer a prescriptive answer to these questions. Rather, I would seek for scholars and activists to recognize that we are not simply dealing here with socially determined materialities, but with a specific condition of legibility that we ourselves help to create for good or bad, such that the distinction between privilege and identity becomes intelligible in certain kinds of identity claims, but not in others.

\section{Autological Gender and Genealogical Race}

Understanding our investment in (re)producing such a condition of legibility requires introspection about why many of us, both POC and not, evidence such a gut reaction against racial self-determination while gender self-determination seems to be much easier to accept irrespective of the (dis)privileges informing individual trans narratives. Part of the answer might lie in the modern emergence of gender and sexuality as expressive of psychic interiority and the truth of the self. Heyes notes that sex, gender, and sexuality have come to be seen as "core ontological differences attaching to individuals" and further, the sex-gender distinction has repositioned gender identity as a matter of individual psychology, inner authenticity and self-expression that might contravene social sex assignment (2009, 148). Conventional cisgender epistemologies of gender conflate assigned sex and gendered essence while trans-inclusive epistemologies challenge this conflation. Both, however, demand that we associate sex/gender with a deeply interior identity, recalling the argument that Foucault famously makes 
about sexuality as a truth we must confess: "sexuality is related . . . to the obligation to tell the truth . . . and of deciphering who one is" $(1988,16)$. Even as trans discourse refuses biological or social criteria for gender determination, the confessional avowal of gender as a core personal identity is perhaps the condition that permits its legibility and ethico-political validation as a self-determined reality: our gendered sense of self-perception must mean something in terms of the ontology of our inner being and correspond with an interiorized selfhood (even if genderqueer or agender) that demands recognition beyond social impediments. Self-determination thus redeploys confessional power, reversing the cissexist idea that sociobiological sex assignment naturally corresponds to an essential unchangeable identity, such that the avowal of gender as an interiorized essence now becomes the basis for social sex-gender recognition. This redeployment is taken to its logical conclusion in an article by Wiley Reading in Everyday Feminism, which argues for the recognition of gender identity as independent of not just sexed embodiment but also gender presentation:

I've let my hair grow out so long that I have to put it in pigtails ... I sound like a girl, right? I'm not. Why? Because I don't identify as one. . . Although gender identity and gender expression can be related . . they don't have to be. . . . Gender identity is internal. . . . It's the word (or words) that you could use to decide yourself that simply make sense to you. . . . Gender identity is internal, deeply-rooted, and a central part of many people's senses of self. (2014; emphasis in original)

Reading thus articulates gender identification as a decisional process that should be absolutely unconstrained by social or material determinations but, simultaneously, it ultimately springs from and is justified on the basis of a "deeply-rooted" individual essence that the subject deciphers and confesses.

In contrast, race is linked more with collective descent than individual subjectivity. Heyes observes that race is seen to derive from ancestral inheritance and is located within a collective genealogical narrative, which renders racial self-determination illegible:

$[\mathrm{M}] \mathrm{y}$ race does not exist only in the moment but depends on my heritage . . . race is taken to be inherited in a way that sex is not. The claim that 'I've always known I was really white inside' is unpersuasive in part because it implicates others; if one's immediate forebears are not white, the claim risks being unintelligible. (2009, 143-144; emphasis in original)

\section{Sealey argues that:}

$[\mathrm{R}]$ ace is really about a relationship-namely, a relationship between actual genetic ancestry ... and the cultural and social signification of that ancestry . . which then allows ancestry to mean certain things. . . . Hence, the role and predicative force of ancestry, in my racial identity, is not biological at all, but rather, social. (2018, 23; emphais in original)

Sealey's framing of race as a "social construction," with social italicized, "emphasizes the status quo's relative imperviousness to individual agency” (24). This argument ignores how ancestry may be recoded through individual and collective agency as well as social transformations: for instance, one's ancestral affiliation may be retrospectively mapped as white or black in ways that contravene the racial designations of one's forebears (Gordon 2018, 15). Further, despite Sealey's insistence that the "predicative force of ancestry" is not biological but social, in her argument, the social signification of inheritance ultimately references "actual genetic ancestry" $(2018,23)$. The definition of ancestry is thus limited in terms of consanguinity over chosen or voluntary kin, reinforcing a normative model of lineage based on blood relations and perpetuating hierarchies of kinship that exclude queer arrangements of family and genealogy.

The association of race with consanguineal ancestry means that the possibility of individualized racial subjectivity outside of one's "actual genetic" genealogy may be dismissed entirely. As Blay says, "transracial identity. . . perpetuates the false idea that it is possible 
to 'feel' a race" (2015). The only legible and valid form of subjective racial identity seems to hinge on the experience of consanguineal belonging, erasing the possibility of non-genetic affiliation with a racialized collectivity. Witness Denene Millner's explanation of why Diallo can never be black: "like diamonds, blackness is created under extreme pressure and high temperature, deep down in the recesses of one's core. It is sitting between your mama's knees on a Saturday night ... It is showing up to the family reunion" (2017). This establishes a deterministic relationship between consanguineal heredity and subjective racial identity, which may also be extended to social position: heredity determines skin colour determines racial privilege (Blay 2015). More constructionist accounts of race that do not see race as biological may also dismiss subjective racial identification. Victoria Anderson (2017), for instance, argues that race as a politically constructed taxonomical system based on fallacious classifications precludes racial identity as an "innate, inner experience" as claimed by Diallo, but is silent on why socially constructed categories cannot be interiorized, as commonly accepted in the case of gender.

The contrast between the individualized determination of gender and the social and/or biological determination of race evokes Elizabeth Povinelli's analytical distinction between autology and genealogy as the dominant forms of discipline in late liberalism (Povinelli 2006; Posocco 2008). Gender self-determination may be understood as a paradigmatic case of autology, by which Povinelli refers to the discursive construction of the autonomous, sovereign and selfdetermining subject (Povinelli 2006). Autology organizes identity based on "a fantasy of self-authorizing freedom . . . what do $I$ think, what do $I$ desire, $I$ am what $I$ am, $I$ am what $I$ want . . . (which is) a phantasmagorical figure of liberalism" (Povinelli and DiFruscia 2012, 80; emphasis in original). However, as we saw above, the autological construction of gender identity is justified and delimited through the operations of confessional power such that self-determination should be free of material determinations and yet rooted in interiorized selfhood. Genealogy, on the other hand, refers to "discourses which stress social constraint and determination in processes of subject constitution and construe the subject as bound by "various kinds of inheritances"” (Posocco 2008).

The ways in which the lines between transrace and transgender are drawn in contemporary debates on transracialism, such that the materiality-subjectivity or privilege-identity distinction operates in one domain but not the other, serves to police and reproduce the autology-genealogy distinction. While the dissociation of interiorized subjectivity from social sexgender assignment and related material (dis)privileges in the case of gender enables the autological project of gender self-determination, the deterministic conflation of sociobiological ancestry, subjective racial identity, and racial (dis)privilege preserves race as resolutely genealogical. The anxious desire to delimit the valid domain of autology and maintain proper distinctions between autology and genealogy is evidenced in the aforementioned contrasting statements by Talusan. She articulates her womanhood as a conscious decision in the face of social contingencies, only to later qualify transgender identity and transition as involuntary and expressive of essential selfhood, in contradistinction to transrace which is cast as an illegitimate exercise in autology without a deep ontological basis: "Dolezal identified as black, but I am a woman" (Talusan 2015). As Reed (2015) notes, "essentialism cuts in odd ways in this saga ... [s]ometimes race is real in a way that sex is not," as an immutable social reality based on biologized ancestry, while sometimes "gender is 'real' in a way that race is not," as the involuntary ontological core of selfhood. However, qualifying Reed, this is not merely "opportunist politics," it is symptomatic of how race and gender are constructed and situated differently with respect to autological and genealogical discourses and modalities of power.

The contrast between the individualized autology of gender and the collective genealogy of race thus might be one of the underlying reasons for the widespread discomfort with transracialism and the race-gender analogy. If the fantasy of autological gender identity 
disguises the operations of confessional power, such autology is constituted and delimited through its distinction from genealogical aspects of selfhood. Whether transracialism is an ethically or ontologically valid phenomenon or not, the separation of autological and genealogical domains of identity ties us to the oppressive generalization of gender as an inevitable "deeply-rooted" essence that we must decipher and confess, in contradistinction to race or ethnicity that is assigned to us or derives from our inherited collective positions. The autology-genealogy separation as applied to race and gender thus works as a disciplinary mechanism through which the subject is constituted within contemporary forms of governance: it ties one to confessional technologies of power in certain aspects of selfhood and to sociobiological inheritance in other aspects.

Inasmuch as many of us derive pleasure or validation from ontological identification, I am not asking for doing away with the autology of gender self-determination as merely a ruse of power. Indeed, the very emergence of this autological discourse marks hardwon struggles against the genealogical regulation of assigned sex-gender. Nor is this an argument for the indiscriminate extension of autology to all domains of identity. I end with the rather more humble proposal that we become more reflexive about how and why we disentangle subjective identity from material difference and social position in some cases but not others, and how our inconsistent usages of the materiality-subjectivity distinction reinforce or reconfigure the governmental demarcation of selfhood into autological and genealogical domains. More reflexive uses of the materiality-subjectivity distinction could help us understand the variable and sometimes contradictory imbrications of identification and social positioning for both gender and race. Such reflexivity might enable a more contextualized approach to contradictory alignments of material position and subjective identification and allow for a more transparent accounting of why scholars and activists may be more accepting of some such identity claims than others, rather than the generalized adjudication of subject positions as per a preset autology/genealogy divide that consigns certain axes of identity to the autological fantasy of self-determination and others to genealogical constraints. Critiques of privileged forms of gender and racial (dis)identification might then also avoid the adjudication of their relative degree of ontological realness or validity, which is perhaps ultimately undecidable.

\section{Endnote}

1. I use "transrace" instead of the more usual adjective "transracial" in order to disambiguate my usage from the sense of "transracial" as pertaining to cross-racial adoptees (see Moyer 2015).

\section{Acknowledgements}

The author would like to thank the anonymous peer reviewers for their encouraging and helpful comments on a previous draft of this article. The author also thanks numerous friends and interlocutors, particularly Lisa Duggan, Srila Roy, and Naomi Greyser, for their engagement with earlier and more informal articulations of some of the ideas contained in this article on social media, which helped the author to develop the argument in its current form. 


\section{References}

Adichie, Chimamanda Ngozi. 2017. "Clarifying." Facebook, March 12, 2017.

https://www.facebook.com/chimamandaadichie/posts /10154893542340944:0.

Allen, Samantha. 2015. "Dolezal's Damaging 'Transracial' Game.” The Daily Beast. June 16, 2015. https://www.thedailybeast.com/dolezals-damagingtransracial-game.

Anderson, Victoria. 2017. "The contradiction at the heart of Rachel Dolezal's 'transracialism." The Conversation. April 11, 2017.

https://theconversation.com/the-contradiction-at-theheart-of-rachel-dolezals-transracialism-75820.

Bauer, Asher. 2010. "Not Your Mom's Trans 101." Tranarchism. November 26, 2010.

https://www.tranarchism.com/2010/11/26/not-yourmoms-trans-101/.

Barrett, Ruth, ed. 2016. Female Erasure: What You Need To Know About Gender Politics' War on Women, the Female Sex and Human Rights. Los Angeles: Tidal Time Publishing.

Blay, Zeba. 2015. "Why Comparing Rachel Dolezal To Caitlyn Jenner Is Detrimental To Both Trans And Racial Progress." HuffPost Black Voices. June 13, 2015. https://www.huffingtonpost.in/entry/rachel-dolezalcaitlyn-jenner_n_7569160.

Borck, C. Ray. 2017. "Negligent Analogies." TSQ: Transgender Studies Quarterly 4 (3-4): 679-684. https://doi.org/10.1215/23289252-4190064.

Callahan, Kat, 2013. "Cis Feminists Need To Understand 'Provisional' Male Privilege." Jezebel. July 14, 2013. https://roygbiv.jezebel.com/cis-feministsneed-to-understand-provisional-male-pri-776071122.

Currah, Paisley. 2015. "How not to stop the transrace/transgender comparison." Paisley Currah.
June 18, 2015.

https://paisleycurrah.com/2015/06/18/how-not-tostop-the-transracetransgender-comparison/.

Dutta, Aniruddha. 2016. "Gatekeeping Transgender." Raiot. October 4, 2016. http://raiot.in/gatekeepingtransgender/.

Dutta, Aniruddha and Raina Roy. 2014. "Decolonizing Transgender in India: Some Reflections.” TSQ: Transgender Studies Quarterly 1 (3): 320-337. https://doi.org/10.1215/232892522685615 .

Firestone, Shulamith. 1970. The Dialectic of Sex: The Case for Feminist Revolution. New York: William Morrow.

Foucault, Michel. 1988. "Technologies of the Self." In Technologies of the Self: A Seminar with Michel

Foucault, edited by Luther H. Martin, Huck Gutman, and Patrick H. Hutton, 16-49. London: Tavistock.

Frank, Robert. 2015. "Most millionaires say they're middle class." CNBC. May 6, 2015.

https://www.cnbc.com/2015/05/06/naires-say-theyremiddle-class.html.

Gordon, Lewis. 2018. "Thinking through Rejections and Defenses of Transracialism." Philosophy Today 62 (1): 11-19. DOI: 10.5840/philtoday201829196.

Green, Kai M. 2015. “'Race and gender are not the same!' is not a Good Response to the 'Transracial'/Transgender Question OR We Can and Must Do Better." The Feminist Wire. June 14, 2015. http://www.thefeministwire.com/2015/06/race-andgender-are-not-the-same-is-not-a-good-response-tothe-transracial-transgender-question-or-we-can-andmust-do-better/.

Heyes, Cressida J. 2009. "Changing Race, Changing Sex: The Ethics of Self-Transformation." In You've Changed: Sex Reassignment and Personal Identity, edited by Laurie Shrage, 135-54. New York: Oxford University Press.

Issue $39.2 / 2018$ 
Jerkins, Morgan. 2015. "Writing, Trans Identity, Race, and All the Poetry: An Interview with Meredith Talusan." The Toast. April 23, 2015. http://thetoast.net/2015/04/23/an-interview-with-meredithtalusan/view-all/.

Koerner, Claudia and Jim Dalrymple II. 2015. "A Civil Rights Leader Has Disguised Herself As Black For Years, Her Parents Say.” Buzzfeed. June 12, 2015. https://www.buzzfeed.com/claudiakoerner/a-civilrights-leader-has-disguised-herself-as-black-foryea?utm_term=.hfLqbvz7a\#.oapX9LwJ7.

Kim, Eun Kyung. 2015. "Rachel Dolezal breaks her silence on TODAY: 'I identify as black'." Today. June 16, 2015. https://www.today.com/news/racheldolezal-speaks-today-show-matt-lauer-after-naacpresignation- $\mathrm{t} 26371$.

Marx, Karl and Friedrich Engels. 1945. The Communist Manifesto. Translated by Samuel Moore. Chicago.

Micah. 2015. "The Gender Playbook: A Guide to Figuring Out Your Non-Binary Identity." Everyday Feminism. September 22, 2015. https:/everydayfeminism.com/2015/09/guidenonbinary-identities/.

Millner, Denene. 2017. "Why Rachel Dolezal Can Never Be Black." NPR Code Switch. March 3, 2017. https://www.npr.org/sections/codeswitch/2017/03/03 1518184030/why-rachel-dolezal-can-never-be-black.

Moyer, Justin Wm. 2015. "Rachel Dolezal draws ire of transracial adoptees." Washington Post. June 17, 2015.

https://www.washingtonpost.com/news/morningmix/wp/2015/06/17/rachel-dolezal-draws-ire-oftransracial-adoptees/.

Orinam. 2016. “The Transgender Persons (Protection of Rights) Bill 2016: Responses from the Trans \& Intersex Communities." http://orinam.net/content/wpcontent/uploads/2016/08/Community-Response-toTG-Bill-20161212pm_Monday_Aug81.pdf.

Open Letter to Hypatia. 2017.

https://archive.is/lUeR4\#selection-71.0-71.11.

Penny, Laurie. 2014. "What the 'Transgender Tipping Point' Really Means." The New Republic. June 28, 2014. https://newrepublic.com/article/118451/whattransgender-tipping-point-really-means.

Povinelli, Elizabeth A. 2006. The Empire of Love: Toward a Theory of Intimacy, Genealogy, and Carnality. Durham: Duke University Press.

Povinelli, Elizabeth A. and Kim Turcot DiFruscia. 2012. "A Conversation with Elizabeth A. Povinelli." Trans-Scripts 2 (2012): 76-90.

Posocco, Silvia. 2008. "The Empire of Love: Review of Elizabeth Povinelli.” Darkmatter 3 (Postcolonial Sexuality).

http://www.darkmatter101.org/site/2008/05/02/theempire-of-love-review-of-elizabeth-povinelli/.

Reed Jr., Adolph. 2015. "From Jenner to Dolezal: One Trans Good, the Other Not So Much." Common Dreams. June 15, 2015.

https://www.commondreams.org/views/2015/06/15/j enner-dolezal-one-trans-good-other-not-so-much\#.

Reading, Wiley. 2014. "Separating Out Gender Identity from Gender Expression.” Everyday

Feminism. May 15, 2014.

https://everydayfeminism.com/2014/05/separatingidentity-expression/.

Richards, Jen. 2017. "What Chimamanda Ngozi Adichie Got Right-And Really Wrong-About Trans Women And Male Privilege." Logo Newnownext. March 18, 2017.

http://www.newnownext.com/chimamanda-ngoziadichie-transgender-woman/03/2017/. 
Sealey, Kris. 2018. "Transracialism and White Allyship: A Response to Rebecca Tuvel." Philosophy Today 62 (1): 21-29. DOI:

$10.5840 /$ philtoday 201829197.

Stryker, Susan. 2015. "Caitlyn Jenner and Rachel Dolezal: Identification, Embodiment, and Bodily Transformation." AHA Today. July 13, 2015. http://blog.historians.org/2015/07/caitlyn-jennerand-rachel-dolezal-identification-embodimentbodily-transformation/.

Talusan, Meredith. 2015. "There is no comparison between transgender people and Rachel Dolezal." The Guardian. June 12, 2015.

https://www.theguardian.com/commentisfree/2015/j un/12/comparison-transgender-people-rachel-dolezal.

Tannehill, Brynn. 2013. "Myths about Gender Confirmation Surgery." Huffington Post. December 8, 2013. http://www.huffingtonpost.com/brynntannehill/myths-gender-confirmationsurgery_b_4384701.html.

THITS (Telangana Hijra Intersex Transgender Samiti). 2016. "Telangana Hijra Intersex Transgender Samiti responds to MSJE Transgender Rights bill (2015).” Accessed June 1, 2018.

http://orinam.net/telangana-samiti-response-msjetrans-rights-bill/.

Thom, Kal Cheng. 2015. "Still Think Trans Women Have Male Privilege? These 7 Points Prove They Don't." Everyday Feminism. October 4, 2015. https://everydayfeminism.com/2015/10/transwomen-male-privilege/.

Tuvel, Rebecca. 2017. "In Defense of Transracialism." Hypatia 32 (2): 263-278.

https://doi.org/10.1111/hypa.12327. 